\title{
Important Factors When Choosing a Career in Public Health
}

\author{
Teri S. Tamayose ${ }^{1}$, Farzin Madjidi ${ }^{2}$, June Schmieder-Ramirez ${ }^{2}$, and Gail T. Rice ${ }^{1}$ \\ ${ }^{1}$ Loma Linda University \\ ${ }^{2}$ Pepperdine University
}

\begin{abstract}
The purpose of this descriptive study was to identify the factors perceived to be important and not important when students are choosing a career. Factors derived from the literature review and suggestions made through the processes of content validity and reliability testing were included when developing the four-point Likert scale survey instrument. The instrument was reviewed by a panel of experts for content validity. In the survey, respondents were asked to indicate the level of importance of statements identified as being influential in making career decisions. Methods: The survey instrument was distributed to 258 Loma Linda University School of Public Health students following a short introduction of the study at the New Student Orientation which took place in Loma Linda, California. A total of 103 surveys were returned. Results: Descriptive statistics were used to report results. Frequencies and means were calculated for each variable and variables were ranked to determine level of importance. Correlation Analysis examined the relationship between variables in the study and Exploratory Factor Analysis determined the factors that emerged from the data. Discussion: The service-related statements showed the highest level of importance for choosing a career in public health. Demographic variables were found to have some impact on responses. Findings from this study should aid in the development of a strategic marketing plan for Loma Linda University School of Public Health.
\end{abstract}

(c) 2004 Californian Journal of Health Promotion. All rights reserved.

Keywords: education, career choice, public health, enrollment management

\section{Introduction}

The purpose of this descriptive study was to identify the factors perceived to be important and not important when students are choosing a career. This study modeled a study conducted at Loma Linda University by Woods (1988), where students were surveyed to determine the factors which influenced their choice of medicine as a career in addition to determining the factors influencing their choice of educational institution. While the study focused on medical students, the pilot study was conducted prior to 1988, with students in the Loma Linda University School of Dentistry. This study provided an opportunity to compare student attitudes among three of the Schools within the Loma Linda University. This ability to compare students among different Schools within the University system was thought to be beneficial for administrators to understand that perhaps not all health-science students are necessarily alike.
The factors influencing medical students may differ greatly than those influencing public health students.

Understanding the factors which motivate individuals to choose a particular career was important to LLUSPH in defining and describing their current students. Comparing these factors with the desired attributes of a public health professional would help create a recruitment strategy which will identify and attract students who will excel in public health.

Public health is a small field within the health science arena in spite of its broad reaching affect on US citizens. Environmental health, epidemiology, nutrition, international health, and health education, are just a few areas of public health effecting most of our lives, and yet, to the general public, the field of public health appears to be a well-kept secret. 
The 1980s to early 1990s were fairly good for public health educational institutions, showing a slow, but steady increase in student enrollment (Katz, 2000). This, however, did not carry over into the mid 1990s and beyond.

There is little information available indicating that studies have been conducted to determine factors influencing career decisions among public health students. A few studies have been conducted in related areas, such as medicine (Woods, 1988), dentistry (Weaver, Haden, \& Valachovic, 2000), nursing (Beck, 2000; Staiger, Auerbach, \& Buerhaus, 2000; Wright, Zerbe, \& Korrniewicz, 2001), and other health professions such as respiratory health (Mishoe, Valeri, \& Beveridge, 1993) and social work (Csikai \& Rozensky, 1997). Overall, it appears that the trend is toward a decline in graduate enrollments in health related fields as well as science and engineering (Southwick, 2000). Enrollment in these non-public health areas have fallen each year from 1993 to 1997, following four decades of annual increases. A continuing admissions decline in these areas may ultimately lead to a shortage of skilled health and science workers that could ultimately hurt society.

The events of September 11, 2001, brought forth many unforeseen and unprecedented challenges to the American people and sparked a renewed interest in public health issues such as bioterrorism, disease prevention, and national security. Public health officials, hospital workers, emergency personnel, and everyday citizens responded to terrorist attacks. More public health workers will be needed in the future to join forces with these governmental entities to protect the United States and its global allies.

For those of us who have already done so, the initial decision to enroll in school appears to be a fairly straight-forward one. First, one makes the decision to attend graduate school, then one must determine which school to attend, apply, and hopefully be accepted. If more than one acceptance is offered, a final selection must be made. Once enrolled, students are faced with a dilemma-whether or not to stay in that particular school. In truth, however, the decision is not at all easy to make. There are many factors internal and external to the individual making the choice which can greatly alter or affect the decision and its impact on one's life. It is easy for institutions to seem unresponsive to these challenges students face because they are consumed with other important issues. According to Kotler and Fox (1995), institutional marketing should address the needs and desires of the students as well as coordinate marketing activities to retain the individuals they seek to attract (pp. 26-27).

The literature concerning enrollment issues in higher education, demographic shifts, marketing issues in higher education, decision-making models, higher education in public health, factors influencing students' career decisions, and factors influencing students' college choice, were reviewed. Numerous factors which might influence an individual's decision to select a career were explored.

It appears that there are numerous factors that influence students in their decision to choose a particular career and to choose a particular educational institution. Included in these factors are new technological trends, innovation for enhancing the education process, economics, tuition costs and student indebtedness, changing demographics of students in general, and the influences of family members, friends, and teachers. It appears to be in the best interest of each educational institution, therefore, to identify those factors that led their students to attend their school. This will allow the development of a more effective and efficient recruitment plan.

Accordingly, the purpose of this descriptive study was determine the factors, if any, which influence a student's decision to choose a career in public health. Factor influencing choice of educational institution were also studied, although, not reported here.

\section{Methods}

In this descriptive study, a survey was used to collect information from students with regard to 
the factors which were perceived to be most important in influencing their choice of a career in public health and their decision to attend LLUSPH. Furthermore, we attempted to describe the current student population so as to identify a target audience for recruitment purposes.

\section{Subject Selection}

During the Fall Quarter, 2002, LLUSPH consisted of 298 registered on-campus students. Approximately 40 of the 298 registered oncampus students were registered for field practice which took place away from the campus. These 40 students were excluded from the population. The population chosen for this study included all 258 registered, on-campus students currently enrolled in LLUSPH but excluded those enrolled in the off-campus sites and those involved in field practice activities away from campus.

\section{Instrumentation}

Factors derived from the literature review, a previous study conducted at Loma Linda University (Woods, 1988) and suggestions made through the processes of content validity and reliability testing were utilized to develop the survey instrument with application to the career of public health. A four-point Likert scale was used to assess these factors as they relate to LLUSPH students. The four-point Likert scale forces respondents to take a position on each question by not providing a benign, middle ground position. Respondents were asked to indicate the level of importance of a number of statements describing potential influences within their decision-making process.

Seventeen variables were included in the survey instrument which have the potential to influence a student's decision to choose a career in public health. Space to add comments was also provided for the student. Optional biographic and demographic information were also requested such as enrollment status, degree sought, age at last birthday, gender, majors, ethnicity, and the identification of the previous community college, college, or university attended. Although this biographic and demographic information was requested, students were given the opportunity to choose to decline completing this portion to ensure confidentiality of the survey instrument.

\section{Content Validity and Reliability}

A panel of three experts in the field of higher education and research methods reviewed the survey instrument to determine the validity of the statements.

Reliability was established by conducting a pilot study to ensure clarity and appropriateness of survey statements, and measuring internal consistency through Cronbach's alpha.

\section{Data Analysis}

Data was analyzed using a database created with the Number Crunching Statistical Software (NCSS) program. Each of the survey instrument responses was manually entered into the computer to form the database. Descriptive statistics such as frequency distributions and means were used to report the results. Correlation Analysis was used to examine the relationship between certain variables in the study. In addition, Exploratory Factor Analysis was used to determine the factors that emerged from the data. Finally, Cronbach's alpha was calculated to determine the internal consistency of the statements in each factor.

\section{Results}

The survey instrument was distributed to 258 LLUSPH students following a short introduction of the study. Only those who volunteered to be in the study submitted completed surveys. Respondents were asked to indicate the level of importance of statements on a four-point Likert scale identified as being influential in making career decisions and choosing an educational institution. A total of 103 surveys were returned.

\section{Demographics of Respondents}

Respondents were asked to report demographic information such as ethnicity, age, gender, degrees, and majors. The survey instrument allowed respondents the option to answer or not answer questions based on their comfort level. Several categories, such as ethnicity, were 
modified for reporting purposes and collapsed options into subcategories.

The majority (66\%) of respondents claimed White and Asian ethnic backgrounds. Reported age of respondents ranged between 21 and 60 years old. Students who were 40 years of age or younger comprised $74.5 \%$ of the respondents. Of the respondents, $80.58 \%$ were female and $19.42 \%$ were male. Eleven percent of respondents were pursuing $\mathrm{BSPH}$ degrees.
Twenty-seven percent were pursuing DrPH degrees and $58 \%$ were pursuing master's degrees.

\section{Career Choice}

The frequency and percentage of respondents indicating a degree of importance of each of the statements having the potential to influence decisions to choose a career in public health are shown in Table 1.

Table 1

Frequency and Percentage of Respondents Indicating Degree of Importance of Statements Having Potential Influence on Decisions to Choose a Career in Public Health $(\mathrm{N}=103)$

\begin{tabular}{|l|c|c|c|c|c|}
\hline \multicolumn{1}{|c|}{ Statements } & $\begin{array}{c}\text { MI } \\
\text { Freq (\%) }\end{array}$ & $\begin{array}{c}\text { I } \\
\text { Freq (\%) }\end{array}$ & $\begin{array}{c}\text { LI } \\
\text { Freq (\%) }\end{array}$ & $\begin{array}{c}\text { NI orNA } \\
\text { Freq (\%) }\end{array}$ & $\begin{array}{c}\text { Total } \\
\text { Freq (\%) }\end{array}$ \\
\hline A family member & $15(14.56)$ & $32(31.07)$ & $16(15.54)$ & $40(38.83)$ & $103(100)$ \\
\hline A friend & $5(4.85)$ & $32(31.07)$ & $20(19.42)$ & $46(44.66)$ & $103(100)$ \\
\hline A high school or college teacher & $7(6.80)$ & $15(14.56)$ & $23(22.33)$ & $58(56.31)$ & $103(100)$ \\
\hline Career counselor/advisor & $11(10.68)$ & $14(13.59)$ & $19(918.45)$ & $59(57.28)$ & $103(100)$ \\
\hline $\begin{array}{l}\text { Advice from a professional school } \\
\text { advisor/admissions officer }\end{array}$ & $12(11.65)$ & $22(21.36)$ & $15(14.56)$ & $54(52.43)$ & $103(100)$ \\
\hline A public health practitioner & $14(13.59)$ & $29(28.16)$ & $20(19.42)$ & $40(38.83)$ & $103100)$ \\
\hline $\begin{array}{l}\text { Brochures or other written material about public } \\
\text { health, including Website }\end{array}$ & $18(17.48)$ & $30(29.13)$ & $27(26.21)$ & $28(27.18)$ & $103(100)$ \\
\hline $\begin{array}{l}\text { Visit to my high school/college by a recruiter or } \\
\text { public health practitioner }\end{array}$ & $4(3.88)$ & $11(10.68)$ & $10(9.71)$ & $78(75.73)$ & $103(100)$ \\
\hline $\begin{array}{l}\text { Field trip to a health science/public health } \\
\text { school }\end{array}$ & $8(7.77)$ & $11(10.68)$ & $15(14.56)$ & $69(66.99)$ & $103(100)$ \\
\hline Opportunities for research in public health & $21(20.39)$ & $27(26.21)$ & $20(19.42)$ & $35(33.98)$ & $103(100)$ \\
\hline $\begin{array}{l}\text { Job opportunities available/financial security for } \\
\text { my family }\end{array}$ & $26(25.24)$ & $24(23.30)$ & $19(18.45)$ & $34(33.01)$ & $103(100)$ \\
\hline $\begin{array}{l}\text { Potential enjoyment of the profession/ } \\
\text { commitment to health improvement }\end{array}$ & $74(71.84)$ & $25(24.28)$ & $1(.97)$ & $3(2.91)$ & $103(100)$ \\
\hline Variety of specialty options within public health & $47(45.63$ & $36(34.95)$ & $13(12.62)$ & $7(6.80)$ & $103(100)$ \\
\hline Field trip to a public health organization setting & $10(9.71)$ & $19(918.45)$ & $16(915.53)$ & $58(56.31)$ & $103(100)$ \\
\hline $\begin{array}{l}\text { Perceived status of employment within a } \\
\text { medical-related field }\end{array}$ & $20(19.42)$ & $36(34.95)$ & $22(21.36)$ & $25(24.27)$ & $103(100)$ \\
\hline \begin{tabular}{l} 
Provide a health/community service to others \\
\hline
\end{tabular} & $67(65.05)$ & $30(29.13)$ & $3(2.91)$ & $3(2.91)$ & $103(100)$ \\
\hline
\end{tabular}

Note: MI is Most Important, I is Important, LI is Less Important, and NA or NI is Not Applicable or Not Important 
Three statements, "potential enjoyment of the profession" (71.84\%), "provide a health/ community service to others" (65.05\%), and "variety of specialty options within public health" (45.63\%) had the highest frequency of "Most Important” responses.

"Visit to my high school/college by a recruiter" (76.73\%), "field trip to a health science/public health school” (66.99\%), “career counselor/ advisor" (57.28\%), "high school/ college teacher," (56.31\%) and "field trip to a public health organization" (56.31\%) show the highest frequency of "Not Important/ Not Applicable" responses.

Mean response to each statement was also calculated and reported in Table 2 and sorted by value from highest to lowest mean of level of importance.

Table 2

Mean Responses of Respondents Indicating Degree of Importance of Statements Having Potential Influence on Decisions to Choose a Career in Public Health (Listed in Descending Order by Mean)

\begin{tabular}{|l|c|}
\hline \multicolumn{1}{|c|}{ Statements } & Mean $^{\mathrm{a}}$ \\
\hline Potential enjoyment of the profession/ commitment to health improvement & 3.650 \\
\hline Provide a health/community service to others & 3.563 \\
\hline Variety of specialty options within public health & 3.194 \\
\hline Perceived status of employment within a medical-related field & 2.495 \\
\hline Job opportunities available/financial security for my family & 2.407 \\
\hline Brochures or other written material about public health, including Website & 2.368 \\
\hline Opportunities for research in public health & 2.330 \\
\hline Opportunities for research in public health & 2.330 \\
\hline A family member & 2.213 \\
\hline Advice from a professional school advisor/admissions officer & 1.922 \\
\hline Field trip to a public health organization setting & 1.815 \\
\hline Field trip to a health science/public health school & 1.592 \\
\hline Career counselor/advisor & 1.776 \\
\hline Visit to my high school/college by a recruiter or public health practitioner & 1.427 \\
\hline
\end{tabular}

${ }^{a}$ Mean calculated based on a four-point Likert scale with 4.0 representing Most Important and 1.0 representing Not Important/ Not Applicable

After frequencies and means were run, exploratory factor analysis with a Varimax rotation was performed to determine how the statements on the instrument clustered factors or constructs. The factor analysis provided a listing of four factors. Items in each factor were held to a minimum eigenvalue of 1.0. The factors in this part of the study accounted for
$99.67 \%$ of the variation in the data.

To measure the internal consistency of each factor, Cronbach's alpha was performed and mean responses for each factor were calculated. Tables 3 reports means and the Cronbach's alpha for each of the factors identified. 
Table 3

Factors Comprising Reasons Why Students Choose a Career in Public Health

\begin{tabular}{|c|c|c|c|}
\hline Factors & Mean $^{\mathrm{a}}$ & $\begin{array}{l}\text { Cronbach’s } \\
\text { alpha }\end{array}$ & Variables \\
\hline \multirow[t]{4}{*}{ Personal contacts } & \multirow[t]{4}{*}{1.78} & \multirow[t]{4}{*}{0.739} & Career counselor/advisor \\
\hline & & & Advice from a professional school advisor/admissions officer \\
\hline & & & A family member \\
\hline & & & Field trip to a health science/public health school \\
\hline \multirow[t]{5}{*}{ Employment prospects } & \multirow[t]{5}{*}{2.56} & \multirow[t]{5}{*}{0.758} & Job opportunities available/financial security for my family \\
\hline & & & Perceived status of employment within a medical-related field \\
\hline & & & Variety of specialty options within public health \\
\hline & & & $\begin{array}{l}\text { Brochures or other written material about public health, including } \\
\text { Website }\end{array}$ \\
\hline & & & Opportunities for research in public health \\
\hline \multirow[t]{2}{*}{ Service } & \multirow[t]{2}{*}{3.60} & \multirow[t]{2}{*}{0.609} & \begin{tabular}{|l}
$\begin{array}{l}\text { Potential enjoyment of the profession/commitment to health } \\
\text { improvement }\end{array}$ \\
\end{tabular} \\
\hline & & & Provide a health/community service to others \\
\hline \multirow{4}{*}{$\begin{array}{l}\text { Prior experience in a } \\
\text { public health setting }\end{array}$} & \multirow[t]{4}{*}{1.79} & \multirow[t]{4}{*}{0.796} & Field trip to a public health organization setting \\
\hline & & & Field trip to a health science public health school \\
\hline & & & Opportunities for research in public health \\
\hline & & & $\begin{array}{l}\text { Visit to my high school/college by a recruiter or public health } \\
\text { practitioner }\end{array}$ \\
\hline
\end{tabular}

${ }^{\mathrm{a}}$ Mean calculated based on a four-point Likert scale.

\section{Discussion}

Based on the means noted in Table 3, it appears that the category of service which includes statements such as "potential enjoyment of the profession/ commitment to health improvement," and "provide a health/ community service to others", is the factor perceived to be most important in influencing choice of career in public health.

Equally important is knowing what factors are perceived as unimportant to students when choosing a career. The majority (74.5\%) of students responding to the age category were under the age of 40 . While service ranked high with all age groups, personal contacts had the lowest influence rating. This could mean that the majority of students had no personal contacts with public health experts, or the experts they had come in contact with had little influence over their career decisions.
All factors were rated slightly higher among females than males with the largest difference in the category of service. Admissions/placement issues was the most evenly rated factor among males and females. However, it should be noted that although factor scores were slightly higher for female respondents, the order of importance of the factors did not change significantly based on gender. For both male and female respondents, service was the most important factor, followed by employment prospects. The only difference was where males scored prior experience in a $\mathrm{PH}$ setting slightly higher than personal contacts and female respondents scored personal contacts slightly higher than prior experience in a PH setting.

Service again was the factor receiving the highest average scores across all ethnic categories with at least a 3.5 mean score or above (based on a four-point Likert scale). Employment prospects also rated high mean 
scores among all respondents. All respondents selected personal contacts and prior experience in a public health setting as the least influential factors in choosing a career in public health.

While the service factor receive a rating of most important within all degree categories, undergraduate students (BSPH) appear to be influenced more by employment prospects, prior experience in a public health setting, and personal contacts and gave higher ratings overall than other students. Graduate level students (MHA, MPH and DrPH) appear to be less influenced by personal contacts and prior experience in a public health setting but gave employment prospects a higher importance rating.

Survey respondents showed great diversity in rating each factor as to its level of importance. Service to others or the opportunity to work within public health for esoteric reasons appears to be the strongest influencing factor affecting decisions to choose a career in public health regardless of age, ethnic background, gender, etc.

There appears to be little or no correlation between the age of respondents and their decisions to choose a career in public health.

The data created by this study should be useful in identifying a student target audience and focusing marketing efforts within the LLUSPH.

\section{Summary}

There are many factors which may influence an individual's decisions, especially when those decisions involve a higher level of risk or perceived risk. While the factors investigated may have varied somewhat from those used in previous studies, they can be grouped into similar broad areas as revealed in the literature. Biological, psychological, and sociological factors, academic environmental factors, and personal values all have considerable influence on career choice.

The information gathered in this study should be useful to students, parents, and career counselors in determining which careers are appropriate as well as which careers are a good match for students. Understanding the influencing factors can also be beneficial in identifying careers which may not be of interest to an individual.

The data collected and analyzed in this study may also have a long-term benefit to the community by encouraging more students to choose careers in public health, thereby graduating more public health professionals who will serve their communities in the United States as well as throughout the world. While there are many individuals working within the fields of public health, there are far fewer who have earned their education within these arenas. These public health professionals are going to become the front-line of defense in future world battles of disease prevention, environmental issues, and bio-terrorism.

A strategic marketing plan emphasizing service opportunities should have a positive affect on enrollment management. Increasing awareness of public health in general and focusing on employment opportunities may also create more interest in public health as a career.

\section{References}

Beck, C. T. (2000). The experience of choosing nursing as a career. Journal of Nursing Education, 39, 320-322.

Csikai, E. L., \& Rozensky, C. (1997). "Social work idealism” and students' perceived reasons for entering social work. Journal of Social Work Education, 33, 529-538.

Katz, W. (2000). ASPH data center (annual data report ). Washington, DC: Association of Schools of Public Health.

Maher, S. (2000). Minutes from the Annual Meeting of the Deans (1092). Chicago: Association of Schools of Public Health. 
Mishoe, S. C., Valeri, K. L., \& Beveridge, L. H. (1993). A survey of high school seniors' career choices: Implications for allied health. Journal of Allied Health, 22(1), 33-43.

Robbins, R. B. (1999). Fewer want to be doctors. Atlanta Business Chronicle, 22(15), 3A.

Southwick, R. (2000). NSF report warns of declining graduate enrollments in science. The Chronicle of Higher Education, 46(44), A28.

Staiger, D. O., Auerbach, D. I., \& Buerhaus, P. I. (2000). Expanding career opportunities for women and the declining interest in nursing as a career. Nursing Economics, 18, 230-236.

Tieman, J. (2000). Med school downer. Modern Healthcare, 30(38), 18-19.

Weaver, R. G., Haden, N. K., \& Valachovic, R. W. (2000). U.S. dental school applicants and enrollees: A ten year perspective. Journal of Dental Education, 64, 867-874.

Wetzel, J. N., O'Toole, D., \& Peterson, S. (1999). Factors affecting student retention probabilities: A case study. Journal of Economics and Finance, 23(1), 45-55.

Woods, P. F. (1988). Factors perceived as influencing choice of medicine as a career and a choice of medical school. Unpublished Dissertation, Loma Linda University, Riverside.

Wright, M. D. G. M., Zerbe, M., \& Korrniewicz, D. M. (2001). A critical-holistic analysis of nursing faculty and student interest in international health. Journal of Nursing Education, 40, 229-232.

\title{
Acknowledgments
}

We wish to acknowledge the following experts in higher education and research methods who reviewed and commented on the survey instrument: Dr. Helen Hopp Marshak, Associate Professor of Health Promotion and Education and Psychology, Loma Linda University, Dr. Michael Poock, Associate Dean for Academic and Student Affairs, The Graduate School, University of North Carolina at Chapel Hill, and Dr. Zak Sabry, Professor of Public Health Nutrition, Division of Health Policy and Management, and Associate Dean, University of California at Berkeley, School of Public Health.

\author{
Author Information \\ Teri S. Tamayose, EdD, MBA* \\ Assistant Professor \\ Director, Recruitment and Marketing \\ Department of Health Administration \\ Loma Linda University \\ School of Public Health \\ Loma Linda, CA 92350 \\ Ph: 909-558-8394 \\ Fax: 909-558-4087 \\ E-Mail: ttamayose@sph.llu.edu \\ Farzin Madjidi, EdD \\ Associate Professor of Research Methods \\ Director, Doctoral Program in Organizational Leadership \\ Graduate School of Education and Psychology \\ Pepperdine University \\ 6100 Center Drive \\ Los Angeles, CA 90045 \\ E-Mail: fmadjidi@pepperdine.edu
}


June Schmieder-Ramirez, $\mathrm{PhD}$

Professor of Education

Graduate School of Education and Psychology

Pepperdine University

6100 Center Drive

Los Angeles, CA 90045

E-Mail: jschmied@pepperdine.edu

Gail T. Rice, EdD, EdS, RN

Associate Professor

Department of Health Promotion and Education

Loma Linda University

School of Public Health

Loma Linda, CA 92350

E-Mail: grice@sph.llu.edu

* corresponding author 